\title{
Knowledge and practices of breastfeeding among rural postnatal mothers in Central India
}

\author{
Bharani A. ${ }^{1}$, Raipurkar S. ${ }^{2}$, Garg N. ${ }^{3}$ \\ ${ }^{1}$ Dr. Anjali Bharani, Assistant Professor, ${ }^{2}$ Dr. Swati Raipurkar, Professor and Head, ${ }^{3}$ Dr. Neha Garg, Junior \\ Resident; all authors are attached with Department of Pediatrics, Index Medical College and Research Centre, \\ Indore, MP, India.
}

Address for Correspondence: Dr. Anjali Bharani, Assistant Professor, Index Medical College, Hospital and Research Centre, Indore. Address: 119, Ravindra Nagar, Indore. E-mail: dr.anjalibharani@gmail.com

\begin{abstract}
Background: Breastfeeding is known to be central in an infant's nutrition and growth worldwide. However, breastfeeding rates have remained low during this crucial period due to various misconceptions and cultural beliefs. This study was planned to assess the knowledge and practices of breast feeding and identify misconceptions regarding breastfeeding in the postnatal mothers from rural central India. Methodology: A cross-sectional observational questionnaire based study was conducted at a tertiary care teaching hospital in rural part of central India. A total of 100 postnatal mothers attending the pediatric out-patient department were enrolled in the study. Subjects were informed about the study, written consent taken and a structured questionnaire was administered to them. Results: About one third (34\%) of the mothers were either illiterate or received only primary education. Only $18 \%$ mothers had received antenatal counseling about breast feeding and only $28 \%$ had their breast examination done. Although majority of the mothers $(86 \%)$ were breastfeeding their babies, only $22 \%$ had initiated breastfeeding within an hour of delivery. Only $70 \%$ mothers knew that exclusive breastfeeding should be given for first six months and only $58 \%$ believed that it should be continued till 2 years age. Only $18 \%$ mothers knew about the correct technique of breastfeeding. Conclusions: This study reveals that the knowledge and practices of postnatal mothers regarding breastfeeding are far from satisfactory. Our study emphasizes the need for education of mothers especially during antenatal visits and whenever the healthcare providers get an opportunity to sensitize them about the correct technique, early initiation and exclusiveness of breastfeeding for first 6 months.
\end{abstract}

Keywords: Breastfeeding, Knowledge, Postnatal mothers

\section{Introduction}

Breastfeeding is the normal way of providing young infants with nutrients they need for healthy growth and development. The WHO recommends exclusive breastfeeding up to 6 months age with continued breast feeding along with appropriate complementary foods upto 2 years age or beyond [1]. Exclusive Breast Feeding (EBF) is defined as infant feeding with human milk without the addition of any other liquids or solids [2].

The Breastfeeding Promotion Network of India (BPNI) was formed in 1991 to promote mother and

Manuscript received: $18^{\text {th }}$ September 2017

Reviewed: $28^{\text {th }}$ September 2017

Author Corrected: $7^{\text {th }}$ October 2017

Accepted for Publication: 14 ${ }^{\text {th }}$ October 2017 child health to through protection, promotion and support of breastfeeding [3]. The rates of breastfeeding have declined worldwide in recent years. Studies in India have also shown a decline in breastfeeding trends [4]. According to the National Family Health Survey (NFHS 4) report the rate of exclusive breastfeeding in Madhya Pradesh continues to be sub-optimal and was only $58 \%$ for $<6$ months old [5]. In India, breastfeeding appears to be influenced by social, cultural, and economic factors. Various misconceptions and cultural beliefs prevail in society which interferes with successful initiation and maintenance of lactation. Poor practices and attitudes toward exclusive breastfeeding have been reported to be among the major 
reasons for poor health outcomes among children, particularly in developing countries. The promotion and acceptance of practices, such as exclusive breastfeeding, are especially important in developing countries with high levels of poverty, and high infant mortality and low access to clean water and adequate sanitation [6]

A number of studies have been done to assess the knowledge and practices of breastfeeding in different parts of the world [7, 8,9].

However, such studies are limited among mothers from rural part of India.

Hence the present study was developed to examine the infant feeding practices and knowledge regarding breast feeding among postnatal mothers from rural central India

\section{Methods}

Place and type of study: This was a crosssectional, questionnaire based, survey study carried out among postnatal mothers who attended immunization clinic / Pediatric Out Patient Department with their children for vaccination / for the treatment of other minor illnesses and satisfied the inclusion criteria, at a tertiary care hospital in rural central India in the month of August and September 2017.

Inclusion criteria- a) Mothers of healthy infants aged between 0-6 months, b) born between 37 and 42 weeks of gestation and c) without major birth defects such as congenital heart disease, cleft lip/ cleft palate and Down syndrome and d) who consented to participate.

Exclusion criteria- Mothers of preterm babies and those with major birth defects and age above 6 months were excluded. A total of hundred mothers were enrolled in the study.
Instruments- Demographic data was collected on participants background eliciting: age, religion, place of residence, employment, education, and family's monthly income, type of delivery, number of children, exclusive breastfeeding, and initiation of breastfeeding.

A structured questionnaire has been used to assess knowledge and practices regarding breastfeeding among postnatal mothers. The breastfeeding knowledge survey consisted of a series of thirty factual questions with possible response as yes/no/ don't know. The questions addressed the following domains: benefits of breastfeeding to mother and child, properties of breast milk, exclusiveness of breastfeeding, practical knowledge, technique of breastfeeding and contraindications to breastfeeding. Approximately half of the thirty questions (serial number: 3, 7, 8, 12, 14, 15, 16, 17, 18, 20, $21,27,29,30$ ) were framed with 'No' as the correct response.

Data collection procedure- After obtaining the permission from hospital authorities, all mothers were given an explanation of the purpose of the study. Written informed consent was taken from mothers who were willing to participate in the study. Data was collected by the investigator through face-to-face interview, in a private room at the treatment facility where the participants were recruited. It took approximately 20 minutes to complete the structured questionnaire. The mothers were educated about their incorrect responses after the completion of questionnaire.

Ethical Consideration- The permission was obtained from the institutional ethics committee. Confidentiality of the study participants was maintained.

Statistical analysis- The data was entered in a excel sheet and analyzed using unpaired t test.

\section{Results}

Sample Details- The sample of the present study comprised of postpartum mothers (100) of whom $68 \%$ ( $n=68)$ belonged to 20-25 years age group. The mean age of the participants was 23.64 \pm 3.48 (Mean $\pm \mathrm{SD}$ ) and average income was between Rs 2500-5000.

The majorities $(80 \%)$ of the patients were Hindus and all were from rural background. Fifty-eight percent of the patients had caesarian delivery. About one third (34\%) of the mothers were either illiterate or received only primary education. Although majority of the mothers (86\%) were breastfeeding their babies, only $22 \%$ had initiated breastfeeding within an hour of delivery. 
Table-1: Socio-demographic characteristics of the participants.

\begin{tabular}{|c|c|c|c|}
\hline Demographic variables & Group & Frequency & Percentage \\
\hline \multirow[t]{4}{*}{ Age in years } & $<19$ & 2 & 2 \\
\hline & $20-25$ & 68 & 68 \\
\hline & $26-30$ & 28 & 28 \\
\hline & $>31$ & 2 & 2 \\
\hline \multirow[t]{3}{*}{ Income } & $<2500$ & 16 & 16 \\
\hline & $2500-5000$ & 64 & 64 \\
\hline & $5000-10000$ & 48 & 48 \\
\hline Marital status & Married & 100 & 100 \\
\hline Background & Rural & 100 & 100 \\
\hline \multirow[t]{2}{*}{ Employment } & Employed & 6 & 6 \\
\hline & Homemaker & 94 & 94 \\
\hline \multirow[t]{4}{*}{ Education } & Illiterate & 14 & 14 \\
\hline & Primary & 20 & 20 \\
\hline & Secondary & 60 & 60 \\
\hline & Graduate & 6 & 6 \\
\hline \multirow[t]{2}{*}{ Type of Delivery } & Normal & 42 & 42 \\
\hline & Caesarian & 58 & 58 \\
\hline \multirow[t]{2}{*}{ Gravida } & Primi & 62 & 62 \\
\hline & Multigravida & 38 & 38 \\
\hline \multirow{2}{*}{$\begin{array}{c}\text { Current breast feeding } \\
\text { practices }\end{array}$} & Yes & 86 & 86 \\
\hline & No & 14 & 14 \\
\hline \multirow{2}{*}{$\begin{array}{l}\text { Breast feeding initiation } \\
\text { within an hour }\end{array}$} & Yes & 22 & 22 \\
\hline & No & 78 & 78 \\
\hline
\end{tabular}

Table 2 shows the mothers knowledge and opinion towards breastfeeding. The majority of the mothers $(84 \%)$ agreed that breastfeeding should be initiated as early as possible or at least an hour of delivery. Majority of them also agreed that colostrum (78\%) was good for the baby and that breast milk builds up immunity of the baby and minimizes the chance of diarrheal/ear infections (92\%).

Almost three-fourth (70\%) of the mothers believed that it had advantages for mothers also like helps in reducing weight and provides long term protection against breast and ovarian cancers. And $82 \%$ had the opinion that breastfeeding was more convenient than formula feeding. Eighty percent mothers believed that breastfeeding does not affect the beauty of the mother

Only $70 \%$ mothers knew that exclusive breastfeeding should be given for first six months and only 58\% believed that it should be continued till 2 years age. About $54 \%$ of the mothers thought that pre-lacteals like honey, sugar water are good for the baby.

Almost $42 \%$ of the mothers lacked knowledge on exclusiveness of breastfeeding and thought that cow's milk may be given to the baby for first few days in mothers having operative deliveries. Only $56 \%$ of the mothers knew that minor fever/ sickness in mother are not true contraindications for breastfeeding.

Only $18 \%$ mothers knew about the correct technique of breastfeeding that both nipple and areola be introduced in babies' mouth for effective suckling by the baby. Also, only $18 \%$ of the mothers knew that in case of separation from the baby mother can express milk in a clean container and store at room temperature for 8 hours so as to be fed to the baby. Sixty percent of the mothers did not know the importance of hind milk and that the baby has to be fed on one side till the breast is emptied out. 
Table-2: Mother's knowledge regarding breastfeeding.

\begin{tabular}{|c|c|c|c|c|}
\hline $\begin{array}{c}\text { S } \\
\text { No }\end{array}$ & Question & $\begin{array}{l}\text { Correct } \\
\text { response }\end{array}$ & No & $\%$ \\
\hline 1 & $\begin{array}{l}\text { Should breastfeeding be started as early as possible (within half to one } \\
\text { hour) in newborns delivered by both normal and caesarian deliveries? }\end{array}$ & Yes & 84 & 84 \\
\hline 2 & $\begin{array}{l}\text { Should first sticky milk that comes in first } 48 \text { hours i.e. colostrums be } \\
\text { given to the baby as it is good? }\end{array}$ & Yes & 78 & 78 \\
\hline 3 & $\begin{array}{l}\text { Should pre-lacteals (first feed given just after birth) like Honey/water be } \\
\text { given to baby as it is good for the newborn? }\end{array}$ & No & 54 & 54 \\
\hline 4 & $\begin{array}{l}\text { Does breast milk protect baby against diarrhea/ ear infections and build up } \\
\text { immunity of the newborn baby? }\end{array}$ & Yes & 92 & 92 \\
\hline 5 & $\begin{array}{l}\text { Does breast milk protect mother against breast, ovarian cancer and helps } \\
\text { in losing weight? }\end{array}$ & Yes & 70 & 70 \\
\hline 6 & $\begin{array}{l}\text { Does exclusive breastfeeding provide a way of contraception to the } \\
\text { mother? }\end{array}$ & Yes & 48 & 48 \\
\hline 7 & $\begin{array}{l}\text { Should cow's milk/ formula feed be given to the baby in the first two days } \\
\text { if the mother has delivered by operative delivery? }\end{array}$ & No & 42 & 42 \\
\hline 8 & $\begin{array}{l}\text { Should water be given to the newborn baby along with breastfeeding } \\
\text { especially during summer months to prevent dehydration? }\end{array}$ & No & 40 & 40 \\
\hline 9 & Should mother feed the baby during fever, cough, and cold? & Yes & 56 & 56 \\
\hline 10 & $\begin{array}{c}\text { Can working mothers express the breast milk and store at room } \\
\text { temperature for } 8 \text { hours so as to be fed to the baby? }\end{array}$ & Yes & 18 & 18 \\
\hline 11 & $\begin{array}{l}\text { Should mothers with hepatitis B or Tuberculosis on treatment feed the } \\
\text { baby with due precautions? }\end{array}$ & Yes & 24 & 24 \\
\hline 12 & $\begin{array}{l}\text { Is it ok to separate mother and baby after Caesarian delivery to allow for } \\
\text { mother to rest? }\end{array}$ & No & 56 & 56 \\
\hline 13 & $\begin{array}{l}\text { Can mother of twins / triplets produce sufficient milk to provide for both/ } \\
\text { all babies? }\end{array}$ & Yes & 38 & 38 \\
\hline 14 & Should mother with low milk output be condemned? & No & 66 & 66 \\
\hline 15 & $\begin{array}{l}\text { Does breast feeding affect image of working mother and is not feasible } \\
\text { for those who plan to join back to work? }\end{array}$ & No & 80 & 80 \\
\hline 16 & Should mother with HIV/ AIDS infection feed the baby? & No & 62 & 62 \\
\hline 17 & $\begin{array}{l}\text { During Breast feeding should only nipple be introduced in babies mouth, } \\
\text { keeping the areola outside for effective sucking by the baby/ }\end{array}$ & No & 18 & 18 \\
\hline 18 & $\begin{array}{l}\text { Should mother feed in only sitting position as other positions are not } \\
\text { correct? }\end{array}$ & No & 28 & 28 \\
\hline 19 & Is burping essential after breastfeeding? & Yes & 96 & 96 \\
\hline 20 & $\begin{array}{c}\text { Is exclusive breastfeeding defined as giving only mother's milk and } \\
\text { nothing else till } 6 \text { months of post- natal life? }\end{array}$ & Yes & 70 & 70 \\
\hline 21 & Should baby be fed every two hours by clock to avoid hypoglycemia? & No & 76 & 76 \\
\hline 22 & $\begin{array}{l}\text { Does keeping baby and mother in the same bed and allowing skin to skin } \\
\text { contact help initiate breast feeding? }\end{array}$ & Yes & 66 & 66 \\
\hline 23 & Can women with smaller breasts breast feed the baby? & Yes & 46 & 46 \\
\hline 24 & Can mothers with retracted nipples breast feed? & Yes & 26 & 26 \\
\hline 25 & Should breast feeding be continued till 2 years of life? & Yes & 58 & 58 \\
\hline 26 & During breast feeding should mothers maintain eye contact with the baby? & Yes & 90 & 90 \\
\hline 27 & Should one stop breast feeding when you start weaning? & No & 66 & 66 \\
\hline 28 & Is breast feeding more convenient than formula feeding? & Yes & 82 & 82 \\
\hline 29 & Is formula feeding as healthy as breast feeding? & No & 86 & 86 \\
\hline 30 & Should mother feed on one side for five minutes and shift to other side? & No & 40 & 40 \\
\hline
\end{tabular}


On comparison of the knowledge scores of mothers among various variables like educational status, type of delivery, gravid status and antenatal counseling, the average scores of mothers were better in those who were literate, had normal delivery, had multigravida status and received antenatal counseling, as shown in Table 3. However, these differences were not statistically significant.

Table-3: Factors affecting mother's knowledge regarding breastfeeding.

\begin{tabular}{|c|c|c|}
\hline 1 & Variable & P value \\
\hline 2 & $\begin{array}{c}\text { Educational status } \\
\text { Literate } \\
\text { Illiterate }\end{array}$ & 0.315 \\
\hline 3 & $\begin{array}{c}\text { Type of delivery } \\
\text { Normal } \\
\text { LSCS }\end{array}$ & 0.480 \\
\hline 4 & $\begin{array}{c}\text { Gravida } \\
\text { Primi } \\
\text { Multigravida }\end{array}$ & 0.436 \\
\hline $\begin{array}{c}\text { Antenatal counseling } \\
\text { Received } \\
\text { Not received }\end{array}$ & 0.40 \\
\hline
\end{tabular}

\section{Discussion}

Majority of the mothers in this study $(92 \%)$ believed that breast milk is the ideal food for the baby and protects the baby against infections. These findings were similar to the study done in Egypt where $94.8 \%$ of the mothers knew about the immune-protective benefits of breast milk [7].

Majority of the mothers also agreed that colostrum $(78 \%)$ was good for the baby and fed it to the baby. These findings were much higher that the study done by Chaudhary et al who reported that only $25 \%$ mothers knew the benefits of colostrums [8].

The advice on breastfeeding should be initiated for all mothers during antenatal visits, as the mother is more receptive during her pregnancy and has good interaction with the health care professionals. The antenatal examination of mother should also include examination of the breasts for inverted nipples, flattened nipples so that any minor problems related to nipple may be corrected during these visits. However, in our study, only 18\% mothers had received antenatal counseling about breast feeding and only $28 \%$ had their breast examination done. This is missed opportunity for sensitizing the mother and readying her for the upcoming responsibility of breastfeeding. Obstetricians should become more proactive in this regard while taking care of other routine antenatal services. In fact, studies have highlighted the proposal of targeting young women early during school years to increase their awareness of breastfeeding [9]. The infant and young child feeding guidelines (IYCF 2016), recommend initiating breastfeeding as early as possible after birth, preferably within one hour [10].

Though majority of mothers believed (84\%) this was correct but only $22 \%$ mothers had actually done it. Most common reasons for delay in initiation of breastfeeding were: delay in shifting the mothers from labor room, babies were kept in neonatal ICU for observation; mothers not motivated enough after caesarian section. The data from various studies in India shows that initiation rates vary from 16 to $54.5 \%$ [11]. This highlights the important fact that health care professionals be made aware of the urgent need to initiate breastfeeding as early as possible after delivery. Also infrastructural plans must be worked out keeping the lactating mothers in mind to promote early initiation of breastfeeding, like rooming in facilities in the labor theatres, ability to feed after caesarian section.

In our study, only $70 \%$ mothers had the knowledge that exclusive breastfeeding is to be done for the first 6 months of life and 58\% were aware that it should be continued till 2 years. This finding is similar to the study done by Karnawat D et al which showed that rural postnatal mothers had poor knowledge about duration of exclusive and total 
breastfeeding [12]. In the recent Millennium development Goals (MDGs) exclusive breastfeeding (EBF) for 6 months was considered as one of the most effective interventions to achieve Millennium Development Goals (MDG-4). Hence, interventions to promote exclusive breastfeeding for 6 months need to be strongly encouraged [13].

Only $18 \%$ of the mothers knew about the correct technique for breastfeeding and about demand feeding. This is similar to the finding in the study done by Pandey D et al where only $28 \%$ of the mothers knew the correct technique of breastfeeding [14]. Improper latching leads to ineffective transfer of milk and leads to common problems like sore nipples which ultimately affect the continuation of exclusive breastfeeding. Sixty percent of the mothers did not know the importance of hind milk and that the baby has to be fed on one side till the breast is emptied out.

Mothers need to know about expressed breast milk so that they can continue to feed their babies and keep up their milk supply in case they are separated from the baby. However, in our study the knowledge about expressed breast milk and its storage was low (18\%). This is also important in context of working mothers if they are planning to join back to work [15].

About $44 \%$ of the mothers in our study thought that mother should not feed the baby during episodes of illnesses. Much higher percentage $(83.4 \%)$ of such misconceptions is reported in other studies [7]. These are potentially harmful beliefs, which could lead to the dangerous effect of abrupt cessation of breastfeeding practice.

Limitations- The present study has limitations such as cross-sectional nature and small sample size. Hence, future research should be planned with larger sample size to correctly identify barriers to exclusive breastfeeding among Indian mothers.

Despite limitations this study would help health care providers in planning interventions to promote breastfeeding practices.

\section{Conclusions}

This study reveals that the knowledge and practices of postnatal mothers regarding breastfeeding is far from satisfactory. The knowledge on early initiation, exclusiveness for first 6 months, correct technique and true contraindications of breastfeeding needs to be particularly emphasized through breastfeeding counseling, whenever healthcare personnel get an opportunity, especially during antenatal visits. We also recommend strengthening the public health education campaigns for promotion of breast feeding.

What this study adds to existing knowledge?This study highlights the gap in the knowledge and practices about breastfeeding among the rural postnatal mothers in central India and also emphasizes the need to improve their knowledge, particularly about early initiation, exclusiveness for first 6 months, correct technique and true contraindications to breastfeeding.

Funding: Nil, Conflict of interest: None initiated, Perission from IRB: Yes

\section{References}

1. WHO. Exclusive breastfeeding for six months best for babies everywhere', World Health Organization 2011. Available from: http://www. who. int. (Accessed on 21 September 2017)

2. WHO. The WHO Global Data Bank on Infant and Young Child Feeding. WHO Nutrition for Health and Development, 2009.Available from: http : //www.who.int. (Accessed on 21 September 2017)

3. Gupta A. BPNI: 10 years of its work.J Indian Med Assoc. 2002 Aug;100(8):512-5.

4. Rasania SK, Singh SK, Pathi S, Bhalla S,Sachdev TR. Breast-Feeding Practices In A Maternal And Child Health Centre In Delhi. Health Popul Perspect Issues. 2003; 26 (3):110-5

5. National Family Health Survey-4; (2015-16). Available at http://rchiips.org/NFHS/pdf /NFHS4 /AP_Fact Sheet.pdf.

6. Magawa R. Knowledge, attitudes and practices regarding exclusive breastfeeding in Southern Africa-Part 2. 2012. (Accessed on 2017 September 21). Available from: http:/ /www. polity. org. za/ article/knowledge-attitudes-and-practices-regarding - exclusive-breastfeeding-in-southern-africa---part1-2012-12-05 
7. Mohammed E S, Ghazawy E R, Hassan E E. Knowledge, Attitude, and Practices of Breastfeeding and Weaning Among Mothers of Children up to 2 Years Old in a Rural Area in El-Minia Governorate, Egypt. J Family Med Prim Care. 2014 Apr-Jun; 3(2): 136-140. doi: 10.4103/ 2249-4863. 137639

8. Chaudhary RN, Shah T, Raja S. Knowledge and practice of mothers regarding breast feeding: A hospital based study. Knowl Pract Breast Feed. 2011; 9:194-200. doi: http://dx.doi.org/10. 3126/ hren.v9i3.5590

9. Nabulsi M. Why are breastfeeding rates low in Lebanon? A qualitative study. BMC Pediatr. 2011 Aug 30;11:75. doi: 10.1186/1471-2431-11-75.

10. Tiwari S, Bharadva K, Yadav B, Malik S, Gangal P, Banapurmath CR, Zaka-Ur-Rab Z, Deshmukh U, Visheshkumar -, Agrawal RK. Infant and Young Child Feeding Guidelines, 2016.Indian Pediatr. 2016 Aug 8;53(8):703-13.

11. Agarwal S, Srivastava K, Sethi V. Maternal and New-born Care Practices Among the Urban Poor in
Indore, India: Gaps, Reasons and Possible Program Options. Urban Health Resource Center, New Delhi, 2007.

12. Karnawat D, Karnawat BS, Joshi A, Kohli GK. Knowledge, attitude \& practices about infant feeding among mothers of urban \& rural areas of Ajmer district. JMR 2015; 1(3): 90-9.

13. Ulak M, Chandyo RK, Mellander L, Shrestha PS, Strand TA. Infant feeding practices in Bhaktapur, Nepal: a crosssectional, health facility based survey. Int Breastfeed J, 2012; 10:1. doi: https: //doi.org/10.1186/1746-4358-7-1

14. Pandey D, Sardana P, Saxena A, Dogra L, Coondoo A, Kamath A. Awareness and Attitude towards Breastfeeding among Two Generations of Indian Women: A Comparative Study.PLoS One. 2015 May 19;10(5):e0126575.doi:10.1371/ journal. pone. 0126575 . eCollection 2015.

15. World Health Organization. Infant and young child feeding Model Chapter for textbooks for medical students and allied health professionals. World Health Organization. 2009.

\section{How to cite this article?}

Bharani A, Raipurkar S, Garg N. Knowledge and practices of breastfeeding among rural postnatal mothers in Central India. Int J Pediatr Res. 2017;4(10):596-602.doi:10.17511/ijpr.2017.i10.03. 